\section{Localized hypothermia influences assessment of recovery from vecuronium neuro- muscular blockade}

Marie L. Young MD, C. William Hanson III MD, Marc J. Bloom MD PhD, Joseph S. Savino MD, Stanley Muravchick MD PhD
The purpose of this study was to determine the extent to which localized hypothermia of a monitored extremity alters the assessment of recovery from vecuronium-induced neuromuscular blockade. Bilateral integrated evoked electromyographic (IEMG) responses were measured in the ulnar distribution of 14 anaesthetized patients who had differing upper extremity temperatures as measured at the adductor pollicis to determine whether localized hypothermia alters the clinical assessment of spontaneous recovery from vecuronium-induced neuromuscular blockade. All patients received general anaesthesia with thiopentone, $\mathrm{N}_{2} \mathrm{O} / \mathrm{O}_{2}$ and opioid; $11 / 14$ patients received isoflurane for blood pressure control. Bilateral adductor pollicis, oesophageal and ambient temperatures, and IEMG evoked response $\left(t_{1}\right)$ expressed as percent unparalyzed control were recorded during the anaesthetic. The difference in evoked response between the warmer and the colder upper extremity was calculated at $25 \%, 50 \%$ and $75 \%$ spontaneous recovery from neuromuscular blockade in the warm extremity. Differences in temperature between extremities ranged from $0.2-11^{\circ} \mathrm{C}$. The difference in IEMG-evoked response between extremities was proportional to the difference in temperature, and there was a direct correlation $(r=0.78$ ) between IEMG response and extremity temperature; IEMG response was absent when extremity temper-

\author{
Key words \\ MEASUREMENT TECHNIQUES: neuromuscular blockade; \\ MONITORING: neuromuscular function; \\ NEUROMUSCULAR RELAXANTS: vecuronium; \\ TEMPERATURE: cooling, hypothermia.
}

From the Department of Anesthesia, School of Medicine of the University of Pennsylvania, Philadelphia, Pennsylvania and the Department of Anesthesia, School of Medicine of the University of Pittsburgh, Pittsburgh, Pennsylvania.

Address correspondence to: Dr. Marie L. Young, Department of Anesthesia, University of Pennsylvania, 3400 Spruce Street, Philadelphia, PA 19104-4283. Accepted for publication 26th July, 1994. ature was less than $25^{\circ} \mathrm{C}$. We concluded that localized hypothermia in the monitored extremity decreases the IEMG-evoked response to vecuronium neuromuscular blockade; the greater the temperature decrease, the less the evoked response. Thus, the administration of nondepolarizing relaxants may be inappropriately influenced by monitoring neuromuscular blockade in a cold extremity, especially if its temperature is $<25^{\circ} \mathrm{C}$.

Cette étude vise à déterminer jusqu'à quel point l'hypothermie locale mesurée sur une extrémité modifie lévaluation au moniteur de la récupération du bloc neuromusculaire induit par le vécuronium. La réponse électromyographique intégrée (EIMG) bilatérale est mesurée dans la distribution cubitale chez 14 patients anesthésiés qui présentent des températures différentes au membre supérieur mesurées à l'adducteur du pouce pour déterminer si l'hypothermie locale modifie l'évaluation de la récupération spontanée du bloc neuromusculaire produit par le vécuronium. Tous les patients sont anesthésiés au thiopentone, $\mathrm{N}_{2} \mathrm{O} / \mathrm{O}_{2}$ et morphiniques, $\mathrm{II}$ patients sur 14 recevant de l'isoflurane pour contrôler la pression artérielle. La température de l'adducteur du pouce mesurée bilatéralement, la température oesophagienne et ambiante, et la réponse évoquée à l'EIMG $\left(t_{1}\right)$ exprimée en pourcentage de la température de l'extrémité d'un contrôle non paralysé sont enregistrés pendant l'ansethésie. La différence de réponse évoquée entre l'extrémité chaude et l'extrémité froide est calculée à $25 \%, 50 \%$ et $75 \%$ de la récupération spontanée de l'extrémité chaude. La différence entre les extrémités varie entre 0,2 et $11^{\circ} \mathrm{C}$. La différence de la réponse évoquée à l'EIMG entre les extrémités est proportionnelle à la différence de température, et on trouve une corrélation directe $(r=0,78)$ entre la réponse à l'EIMG et la température de l'extrémité; la réponse à l'EIMG est absente quand la température de l'extrémité est inférieure à $25^{\circ} \mathrm{C}$. Nous en concluons que lhypothermie de l'extrémité monitorée diminue la réponse évoquée du bloc neuromusculaire provoqué par le vécuronium; plus la baisse de température est importante, moindre est la réponse évoquée. Ainsi, l'administration de myorelaxants non dépolarisants peut être influencée faussement par le monitorage du bloc neuromusculaire d'une extrémité froide, surtout si la température esi plus basse que $25^{\circ} \mathrm{C}$. 
Depression of the evoked response to nondepolarizing neuromuscular blockade during hypothermia has been demonstrated in animals and in patients subjected to mild to moderate generalized hypothermia. ${ }^{1-6}$ Our clinical observations suggested that in patients receiving vecuronium for maintenance of muscle relaxation, the magnitude of the neuromuscular-evoked response in an exposed cold extremity was smaller than that observed in the extremity that was kept warm. Hypothermia of an exposed monitored body part in an otherwise normothermic patient is not uncommon in the operating room, thus the effect of low temperature in the monitored extremity may alter the management of neuromuscular blockade. The purpose of this study was to measure and compare integrated evoked electromyographic (IEMG) responses between upper extremities of differing temperatures in patients receiving vecuronium to determine the extent to which localized hypothermia alters the assessment of recovery from neuromuscular blockade.

\section{Methods}

After receiving approval from the institution's Committee on Studies Involving Human Beings, we studied 14 ASA physical status I-III neurosurgical patients, aged 20-65 yr, with non-lateralizing neurological examination scheduled for elective craniotomy or laminectomy. The arm into which the intravenous catheter was inserted was maintained warm, and intravenous fluids were warmed to body temperature with a blood warmer. The blood pressure cuff was also placed on the warm arm. The skin over the ulnar aspect of each arm was prepared with isopropyl alcohol, and surface electrodes (3M Red Dot) were placed at least $15 \mathrm{~min}$ before IEMG data collection to maximize conductance. Temperature was measured with surface thermistors applied over the adductor pollicis in each hand and shielded from ambient thermal effects with YSI 4009 heat-reflecting shields (Yellow Springs Instrument).

Anaesthesia was induced with thiopentone, $70 \% \mathrm{~N}_{2} \mathrm{O}$ in $30 \% \mathrm{O}_{2}$, intravenous or intratracheal lidocaine, fentanyl 5-7 $\mu \mathrm{g} \cdot \mathrm{kg}^{-1}$ or meperidine $1-3 \mathrm{mg} \cdot \mathrm{kg}^{-1}$. Supramaximal train-of-four $(0.5 \mathrm{~Hz})$ stimuli of $0.1 \mathrm{msec}$ duration were delivered to the ulnar nerve at the wrist of both arms during induction and at $20 \mathrm{sec}$ intervals thereafter for the remainder of surgery. The signal was generated and the evoked responses processed by Datex NMT 221 (Puritan-Bennett) IEMG monitors, one attached to each arm. The IEMG activity was measured over the ulnar distribution of each hand. Evoked response $\left(t_{1}\right)$ was expressed as a percent of unparalyzed control-evoked response.

After control IEMG data were obtained, vecuronium was administered for muscle relaxation in a bolus of
$0.05-0.08 \mathrm{mg} \cdot \mathrm{kg}^{-1}$, followed by an infusion adjusted to keep the evoked response of the warmer arm at $10 \%$ of unparalyzed control. Isoflurane was administered (0.1-0.6\% inspired) in 11 patients as needed for control of blood pressure. The contralateral arm was deliberately cooled to a surface temperature no lower than $22^{\circ} \mathrm{C}$ by exposure to ambient temperature or by combinations of ice and air convection. Direct contact of ice and skin covering the ulnar nerve was avoided. Bilateral adductor pollicis, oesophageal and ambient temperatures, as well as the evoked response in each arm, were recorded throughout surgery.

The evoked response $\left(t_{1}\right)$ in the warm extremity was measured in each patient at $25 \%, 50 \%$ and $75 \%$ spontaneous recovery. Simultaneously, the $t_{1}$ was measured in the cold extremity, then the difference in spontaneous recovery between cold and warm extremity was calculated for each patient. Analysis of these differences was made using the Mann-Whitney $U$ test, rank sum difference in temperature versus evoked twitch height and linear regression analysis. Absolute temperature in each extremity was also compared at each recovery point, with the cold extremity evoked response expressed as a percentage of the warm extremity evoked response for each patient. This relationship was correlated with absolute cold extremity temperature. A $P$ value of $<0.05$ was used as a criterion of statistical significance.

\section{Results}

Mean oesophageal temperature for all patients studied was $35.8 \pm 0.62^{\circ} \mathrm{C}$. Mean warm arm temperature was $32.9 \pm 1.3^{\circ} \mathrm{C}(\mathrm{SD})$, and cold arm temperature as measured at the adductor pollicis ranged between 22 and $33.5^{\circ} \mathrm{C}$. Mean ambient temperature was $21.8 \pm 0.9^{\circ} \mathrm{C}$.

The evoked response $\left(t_{1}\right)$ at $25 \%, 50 \%$ and $75 \%$ spontaneous recovery from neuromuscular blockade as well as the temperature difference between extremities for each patient are presented in the Table. The difference in temperature between the upper extremities of each patient ranged from $0.2-11^{\circ} \mathrm{C}$, and the difference in $t_{1}$ increased with decreasing cold extremity temperature. Figure 1 shows the magnitude of the evoked response in the cold extremity as a percentage of the measured response in the warm extremity during recovery. Each data point represents the average $t_{1}$ cold $/ t_{1}$ warm of an individual $\pm S D$, since the values were similar at each of the measured recovery points. Linear regression analysis at $25 \%, 50 \%$ and $75 \%$ spontaneous recovery also showed a positive correlation between cold extremity temperature and the magnitude of the IEMG response $(r=0.78)$. All patients with cold extremity temperatures $\angle 25^{\circ} \mathrm{C}$ showed no clinical evidence of spontaneous recovery in the cold arm despite steady recovery in the warm extremity. The 
TABLE Comparison of evoked response at $25 \%, 50 \% \& 75 \%$ recovery from neuromuscular blockade

\begin{tabular}{|c|c|c|c|c|c|c|c|}
\hline Patient & $\begin{array}{l}t_{1} \text {-warm } \\
25 \%\end{array}$ & $\begin{array}{l}t_{1} \text {-cold } \\
25 \%\end{array}$ & $\begin{array}{l}t_{l} \text {-warm } \\
50 \%\end{array}$ & $\begin{array}{l}t_{1} \text {-cold } \\
50 \%\end{array}$ & $\begin{array}{l}t_{1} \text {-warm } \\
75 \%\end{array}$ & $\begin{array}{l}t_{1} \text {-cold } \\
75 \%\end{array}$ & $T_{\text {warm }}-T_{\text {cold }}\left({ }^{\circ} \mathrm{C}\right)$ \\
\hline 1 & 25 & 12.5 & 50 & 37.5 & 75 & 50 & 2.00 \\
\hline 2 & 25 & 0 & 50 & 0 & 75 & 0 & 8.00 \\
\hline 3 & 25 & 6.25 & 50 & 10 & 75 & 25 & 7.00 \\
\hline 4 & 25 & 6.25 & 50 & 18.5 & 75 & 25 & 6.50 \\
\hline 5 & 25 & 25 & 50 & 50 & 75 & 75 & 3.00 \\
\hline 6 & 25 & 6.25 & 50 & 25 & 75 & 50 & 4.00 \\
\hline 7 & 25 & 8 & 50 & 18.5 & 75 & 37.5 & 4.00 \\
\hline $8^{*}$ & 25 & 0 & 50 & 0 & 75 & 5 & 10.00 \\
\hline 9 & 25 & 12.5 & 50 & 33 & 75 & 65 & 8.50 \\
\hline 10 & 25 & 0 & 50 & 0 & 75 & 0 & 6.50 \\
\hline 11 & 25 & 12.5 & 50 & 18 & 75 & 30 & 2.20 \\
\hline $12^{*}$ & 25 & 0 & 50 & 0 & 75 & 0 & 11.00 \\
\hline $13^{*}$ & 25 & 18 & 50 & 30 & 75 & 50 & 0.20 \\
\hline 14 & 25 & 12.5 & 50 & 37.5 & 75 & 62.5 & 2.00 \\
\hline
\end{tabular}

Unit values for evoked response $\left(t_{1}\right)$ are measured height.

*Patients who received isoflurane.

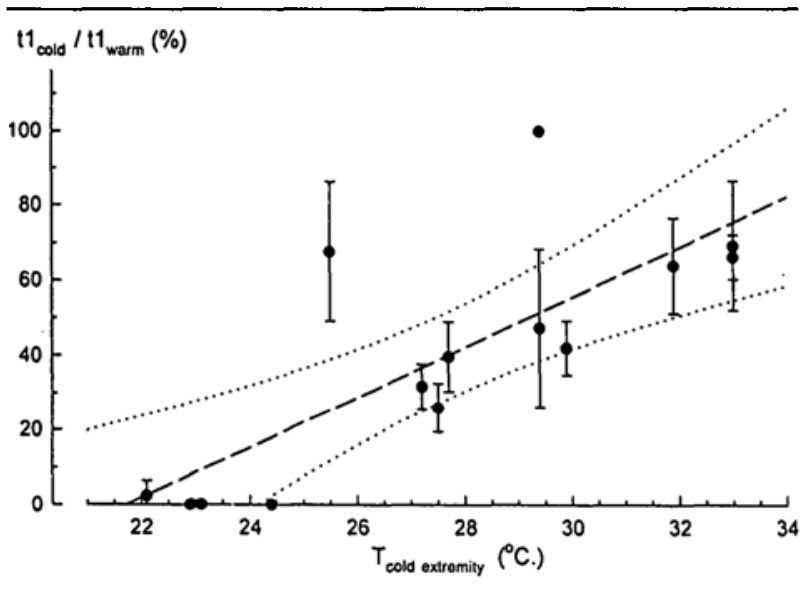

FIGURE 1 Relationship between cold arm temperature $\left({ }^{\circ} \mathrm{C}\right)$ and the magnitude of its IEMG evoked response, expressed as a percentage of the warm arm evoked response $\left(t_{1}\right.$ cold $/ t_{1}$ warm); $t_{1}$ values and cold extremity temperatures are the averages $\pm \mathrm{SD}$ of the measurements at $25 \%, 50 \%$ and $75 \%$ spontaneous recovery from neuromuscular blockade for each patient. Dotted lines represent $95 \%$ confidence intervals; $r=0.78$.

evoked responses in the 11 patients who received isoflurane in addition to $\mathrm{N}_{2} \mathrm{O} / \mathrm{O}_{2}$, narcotic and relaxant were similar to the three patients who did not. The correlation between increased disparity in cold and warm extremity $t_{1}$ and increased temperature difference is also demonstrated in Figure $2(r=0.71)$.

Figure 3 illustrates IEMG recordings from two patients, one in whom the extremity temperatures were 35.1 and $33.0^{\circ} \mathrm{C}\left(\Delta \mathrm{Temp}=2.1^{\circ} \mathrm{C}\right)$, and the other in whom the temperatures were 29.6 and $23.0^{\circ} \mathrm{C}(\Delta \mathrm{Temp}=$ $6.6^{\circ} \mathrm{C}$ ). Differences in the magnitude of the $t_{1}$ to neuromuscular blockade were directly related to extremity

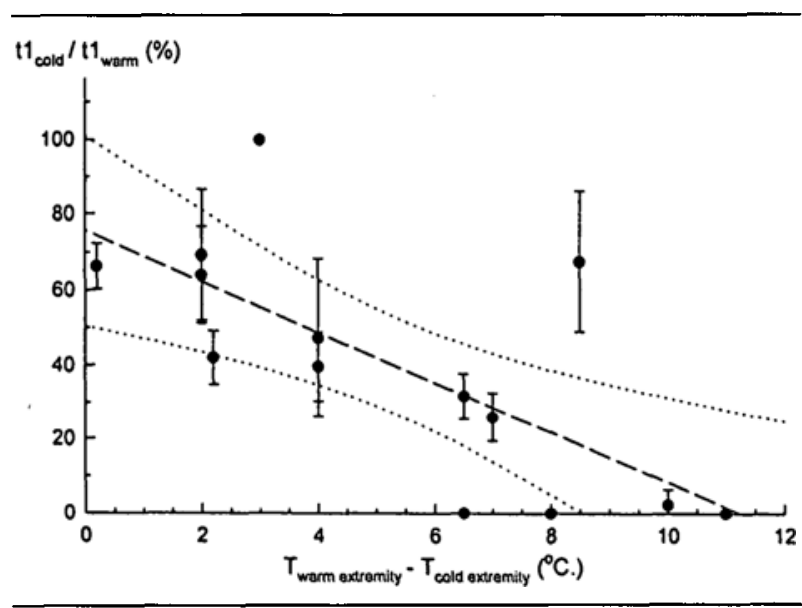

FIGURE 2 Average $t_{1}$ cold $/ t_{1}$ warm \pm SD (at $25 \%, 50 \%$ and $75 \%$ spontaneous recovery) for each patient as a function of increasing difference in temperature between extremities. Dotted lines represent 95\% confidence intervals; $r=0.71$.

temperature. The rate of spontaneous recovery of observed $t_{1}$ was similar in the extremities of patients with a small temperature difference; disparity in rate of recovery between extremities increased as difference in temperature increased. The decrease in measured $t_{1}$ paralleled the decrease in extremity temperature.

\section{Discussion}

Our findings demonstrate a temperature-dependent decrease in evoked response to vecuronium included neuromuscular blockade if the monitored extremity is cold. Hypothermia in the absence of muscle relaxants has been demonstrated to affect nerve conduction as well as motor 
(a)
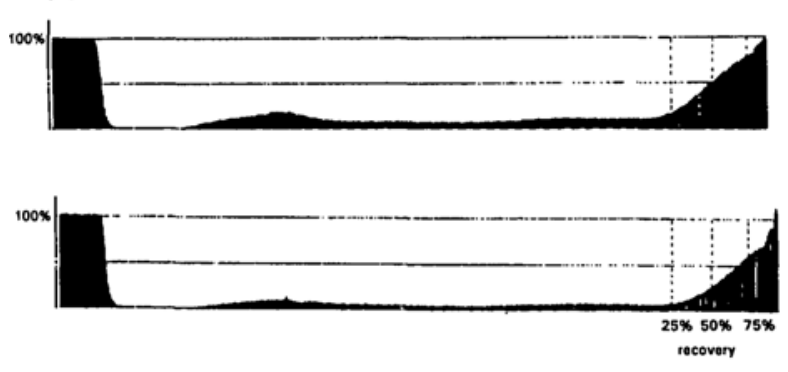

(b)
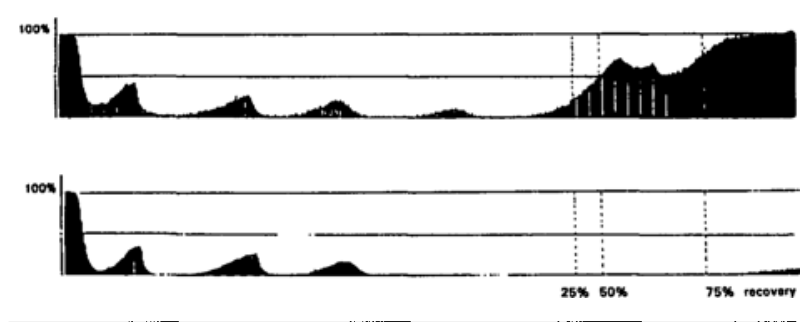

FIGURE 3 Differences in IEMG recordings during spontaneous recovery from neuromuscular blockade in (a) a patient with arm temperatures of $35.1^{\circ} \mathrm{C}$ (top) and $33.0^{\circ} \mathrm{C}$ (bottom) $\left(\Delta \mathrm{T}=2.1^{\circ} \mathrm{C}\right.$ ), and (b) a patient with arm temperatures of $29.6^{\circ} \mathrm{C}$ (top) and $23.0^{\circ} \mathrm{C}$ (bottom) $\left(\Delta \mathrm{T}=6.6^{\circ} \mathrm{C}\right)$. Dashed lines represent $25 \%, 50 \%$ and $75 \%$ recovery points.

response to neural stimulation through various mechanisms. Lowering temperature from $39^{\circ} \mathrm{C}$ to $27^{\circ} \mathrm{C}$ decreased the rate of acetylcholine hydrolysis to $83 \%$ of control in an in vitro model. ${ }^{7}$ Decreases in temperature decrease the speed of neural conduction, as shown in human studies of peroneal motor nerve conduction velocity, where a decrease in muscle temperature from 35 to $23.5^{\circ} \mathrm{C}$ resulted in a $50 \%$ reduction in nerve conduction velocity. ${ }^{8}$ Effects on the motor response to electrical stimulation may involve slowing of impulse propagation over muscle fibre or a direct effect on muscle fibre membranes. ${ }^{9}$ While localized cooling of an extremity in animal models and unanaesthetized humans increases muscle action potentials, decreased muscle contractility also occurs, presumably due to the effect of low temperature on the contractile apparatus. ${ }^{10,11}$ Peripheral cooling to $27-32^{\circ} \mathrm{C}$ in anaesthetized humans produces a linear relationship between skin temperature, twitch tension and train-offour measurements. ${ }^{12}$

A number of studies have reported augmentation or prolongation of nondepolarizing neuromuscular blockade with hypothermia using a variety of agents. ${ }^{1-6}$ Studies of cardiopulmonary bypass-induced hypothermia reported attenuation of neuromuscular blockade with alcuronium, d-tubocurarine and paancuronium and enhancement of blockade with atracurium and vecuronium. ${ }^{13,14}$ Differences in response to measurement of neuromuscular blockade proportional to temperature differences between extremities in patients receiving atracurium have also been described. ${ }^{15}$ An apparent "recurarisation," or decreased response to integrated electromyogram stimulation, has been observed in patients following hypothermic cardiopulmonary bypass, which was presumably due to the decrease in extremity temperature as the core and peripheral temperatures equilibrated after discontinuation of rewarming. ${ }^{16}$

Several mechanisms have been proposed for both potentiation and antagonism, including changes in biliary and renal excretion, changing drug volumes of distribution, altered local diffusion receptor affinity, changes in $\mathrm{pH}$ at the neuromuscular junction, ${ }^{17}$ and the net effect of cooling on the various components of neuromuscular transmission. $3,5,7,10,18-20$ Whether the increase in neuromuscular blockade in the presence of both hypothermia and nondepolarizing muscle relaxants is additive or due to hypothermia alone remains to be determined.

Another potential mechanism for apparent delayed recovery from neuromuscular blockade in a cold monitored extremity is the alteration of the pharmacodynamics of muscle relaxants due to vasoconstriction and local haemodynamic changes. Localized hypothermia of the monitored extremity may affect the distribution of blood flow such that elimination of the muscle relaxant is delayed. However, determination of the possible influence of this phenomenon was beyond the scope of this clinical investigation.

We did not detect a difference in recovery from neuromuscular blockade between the 11 patients who received isoflurane and the three patients who did not. However, the number of patients studied is too small to test this observation statistically. Isoflurane has been reported to prolong recovery from vecuronium blockade when given in inspired concentrations greater than $0.9 \%{ }^{19}$ Other investigators have shown no effect of isoflurane on the duration of and recovery from neuromuscular blockade when the inspired concentration was $0.5 \%,{ }^{21}$ findings similar to ours.

The effect of temperature on skin impedance has been suggested as a causal factor in "apparent" neuromuscular blockade when surface electrodes are used. ${ }^{16,22}$ In our investigation, skin electrodes were applied at least $15 \mathrm{~min}$ before control IEMG data were obtained and the arms were carefully wrapped and immobilized to permit satisfactory electrical contact and IEMG signal. These manoeuvres stabilize baseline measurements and decrease motion artifact. ${ }^{23}$

Evaluation of the relationship between measurements of muscle and skin temperatures has yielded conflicting results. Heier et al. concluded that skin temperature measurements do not reliably predict the temperature of the 
adductor pollicis, based on measurements of skin temperature using a $1-\mathrm{cm}$ diameter self-sticking probe. ${ }^{24}$ Muravchick et al. found very close agreement between thumb or forearm muscle temperature and thenar skin temperature using a thermistor needle and flat thermistor probe, respectively. ${ }^{25}$ Eriksson $e t$ al. found a close agreement between skin and muscle temperatures in anaesthetized humans in a skin temperature range of $32-27^{\circ} \mathrm{C}$. ${ }^{14}$ Smith also found agreement between subcutaneous and intramuscular temperature measurement. ${ }^{26}$ We used shielded thermistor probes for measurement of skin temperature like those used by Muravchick. ${ }^{25}$ Perhaps the discrepancy in the findings of these investigators results from different techniques for temperature measurement.

Measurements of IEMG have been demonstrated to correlate with mechanical measurements of nondepolarizing blockade during normothermia. ${ }^{27}$ However, mechanical measurements may lag behind IEMG during recovery. ${ }^{28}$ Mechanical recovery of neuromuscular blockade may be prolonged by hypothermia while electrical recovery is not, thus neuromuscular transmission per se would not be affected. ${ }^{6}$ We have demonstrated that assessment of neuromuscular transmission as measured by IEMG is affected in extremities with temperatures $<31^{\circ} \mathrm{C}$.

Our goal was to duplicate conditions found in the clinical environment with cool operating rooms, exposed extremities and air currents. Placement of a small fan directing air flow over the arm effectively lowered its temperature. Active or passive cooling has been demonstrated to produce comparable decreases in twitch tension. ${ }^{24}$

The mechanical response of the adductor pollicis muscle to ulnar nerve stimulation has been shown to be unaffected by temperature when the adductor pollicis temperature is maintained greater than $35.2^{\circ} \mathrm{C}$ in unparalyzed patients. ${ }^{24}$ However, maintenance of body temperature at this level may be difficult at times and undesirable in those instances where mild hypothermia may be preferable. ${ }^{29,30}$

In summary, this study demonstrates that localized hypothermia in the monitored extremity can influence the assessment of recovery from vecuronium-induced neuromuscular blockade. This has important clinical implications, insofar as the patient's level of neuromuscular blockade is usually monitored in an exposed, accessible arm which may be significantly colder than the rest of the body. Specifically, if administration or reversal of nondepolarizing relaxants is based on monitoring in a cold extremity, (1) an inadequate degree of neuromuscular blockade may exist, and (2) patients may be presumed (incorrectly) not to be "ready" for reversal of neuromuscular blockade. Monitoring of neuromuscular blockade in an arm $<25^{\circ} \mathrm{C}$ may result in the inability to obtain any evoked response.

\section{Acknowledgements}

The authors wish to thank Ms. Maryette Muroff for her assistance in preparation of this manuscript.

\section{References}

1 Miller RD, Van Nyhuis LS, Eger EI II. The effect of temperature on a $d$-tubocurarine neuromuscular blockade and its antagonism by neostigmine. J Pharmacol Exp Ther 1975; 195: 237-41.

2 Miller RD, Roderick $L L$. Pancuronium-induced neuromuscular blockade, and its antagonism by neostigmine, at 29,37 , and $41^{\circ} \mathrm{C}$. Anesthesiology 1977; 46: 333-5.

3 Miller RD, Agoston S, van der Pol F, Booij LHDJ, Crul $J F$, Ham J. Hypothermia and the pharmacokinetics and pharmacodynamics of pancuronium in the cat. J Pharmacol Exp Ther 1978; 207: 532-5.

4 Park WY, Macnamara TE. Temperature change and neuromuscular blockade by $d$-tubocurarine or pancuronium in man. Anesthesiology 1979; 50: 161-3.

5 Ham J, Miller RD, Benet LZ, Matteo RS, Roderick LL. Pharmacokinetics and pharmacodynamics of $d$ tubocurarine during hypothermia in the cat. Anesthesiology 1978; 49: 324-9.

6 Ham J, Stanski DR, Newfield P, Miller RD. Pharmacokinetics and dynamics of $d$-tubocurarine during hypothermia in humans. Anesthesiology 1981; 55: 631-5.

7 Foldes FF, Kuze S, Vizi ES, Deery A. The influence of temperature on neuromuscular performance. Journal of Neural Transmission 1978; 43: 27-45.

8 de Jong $R H$, Hershey WN, Wagman IH. Nerve conduction velocity during hypothermia in man. Anesthesiology 1966; 27: 805-10.

9 Denys EH. AAEM Minimonograph \#14: the influence of temperature in clinical neurophysiology. Muscle Nerve 1991; 14: 795-811.

10 Thornton RJ, Blakeny C, Feldman SA. The effect of hypothermia on neuromuscular conduction (Abstract). $\mathrm{Br} J$ Anaesth 1976; 48: 264.

11 Ricker K, Hertel G, Stodieck G. Increased voltage of the muscle action potential of normal subjects after local cooling. J Neurol 1977; 216: 33-8.

12 Eriksson LI, Lennmarken C, Jensen E, Viby-Mogensen J. Twitch tension and train-of-four ratio during prolonged neuromuscular monitoring at different peripheral temperatures. Acta Anaesthesiol Scand 1991; 35: 247-52.

13 Buzello W, Schluermann D, Pollmaecher T, Spillner G. Unequal effects of cardiopulmonary bypass-induced hypothermia on neuromuscular blockade from constant infusion of alcuronium, $d$-tubocurarine, pancuronium, and vecuronium. Anesthesiology 1987; 66: 842-6. 
14 Denny NM, Kneeshaw JD. Vecuronium and atracurium infusions during hypothermic cardiopulmonary bypass. Anaesthesia 1986; 41: 919-22.

15 Thornberry EA, Mazumdar B. The effect of changes in arm temperature on neuromuscular monitoring in the presence of atracurium blockade. Anaesthesia 1988; 43: 447-9.

16 Fox MA, Hunter JM. Apparent postoperative recurarisation (Letter). Anaesthesia 1986; 41: 879-80.

17 Ono $K$, Nagano $O$, Ohta $Y$, Kosaka $F$. Neuromuscular effects of respiratory and metabolic acid-base changes in vitro with and without nondepolarizing muscle relaxants. Anesthesiology 1990; 73: 710-6.

18 Hubbard JI, Jones SF, Landau EM. The effect of temperature change upon transmitter release, facilitation and posttetanic potentiation. J Physiol 1971; 216: 591-609.

19 Heier T, Caldwell JE, Sessler DI, Miller RD. Mild intraoperative hypothermia increases duration of action and spontaneous recovery of vecuronium blockade during nitrous oxide-isoflurane anesthesia in humans. Anesthesiology 1991; 74: 815-9.

20 Holmes PEB, Jenden DJ, Taylor DB. The analysis of the mode of action of curare on neuromuscular transmission; the effect of temperature changes. J Pharmacol Exp Ther 1951; 103: 382-402.

21 Eriksson LI, Staun P, Lennmarken C. The influence of $0.5 \%$ isoflurane on a vecuronium-induced neuromuscular blockade. Acta Anaesthesiol Scand 1989; 33: 309-12.

22 Winkel J, Jørgensen $K$. Significance of skin temperature changes in surface electromyography. Eur J Appl Physiol 1991; 63: 345-8.

23 Lee $V$, Chen J. Caution in making clinical recommendation based on electromyographic measurements (Letter). Anesthesiology 1986; 64: 529-30.

24 Heier T, Caldwell JE, Sessler DI, Kitts JB, Miller RD. The relationship between adductor pollicis twitch tension and core, skin, and muscle temperature during nitrous oxide-isoflurane anesthesia in humans. Anesthesiology 1989; 71: 381-4.

25 Muravchick $S$, Conrad DP, Vargas A. Peripheral temperature monitoring during cardiopulmonary bypass operation. Ann Thorac Surg 1980; 29: 36-41.

26 Smith NT. Subcutaneous, muscle, and body temperatures in anesthetized man. J Appl Physiol 1962; 17: 306-10.

27 Kopman AF. The dose-effect relationship of metocurine: the integrated electromyogram of the first dorsal interosseous muscle and the mechanomyogram of the adductor pollicis compared. Anesthesiology 1988; 68: 604-7.

28 Weber $S$, Muravchick $S$. Electrical and mechanical trainof-four responses during depolarizing and nondepolarizing neuromuscular blockade. Anesth Analg 1986; 65: 771-6.

29 Berntman $L$, Welsh FA, Harp JR. Cerebral protective effect of low-grade hypothermia. Anesthesiology 1981; 55: 495-8.
30 Milde $L N$. Clinical use of mild hypothermia for brain protection: a dream revisited. J Neurosurgical Anesthesiology 1992; 4: 216-20. 